\title{
Política Estadual e Desigualdade: Por Que alguns Estados Redistribuem Mais do que Outros?*
}

\author{
Natália Guimarães Duarte Sátyro \\ Universidade Federal de Minas Gerais (UFMG), Minas Gerais, Brasil
}

\section{INTRODUÇÃO}

D or que alguns países redistribuem mais do que outros? E, interna1 mente, por que alguns estados redistribuem mais do que outros? Em recente trabalho, Iversen e Soskice (2006) analisam por que alguns governos democráticos são mais propensos à redistribuição de renda do que outros. Os autores mostram que sistemas eleitorais exercem um papel importante porque formatam a natureza dos partidos políticos e a composição das coalizões governamentais, e as características desse sistema político-partidário impactam na redistribuição de riquezas. Para justificar a necessidade de seu estudo os autores começam por mostrar a variância entre as taxas de redução da pobreza e da desigualdade entre alguns países democráticos no período analisado. Para a elaboração deste trabalho, tal como os autores citados, retiro minhas

\footnotetext{
* Versões parciais deste trabalho foram apresentadas no 7ํㅡㄹ Encontro da Associação Brasileira de Ciência Política (ABCP), em Recife, 4-7 de agosto de 2010; no First Seminar on Exchanging Data and Skills on Place Inequality: A UK-Brazilian Collaboration, em Edimburgo, setembro de 2010 e, posteriormente, na Conferência da IPSA-ECPR - Whatever Happened to North-South?, em São Paulo, fevereiro de 2011. Neste percurso, beneficiei-me dos comentários de Marta Arretche, Eduardo Marques, André Borges e Gabriela Tarouco. Agradeço imensamente a todos pela colaboração e os isento de quaisquer responsabilidades. Agradeço ainda à Fundação de Amparo à Pesquisa do Estado de Minas Gerais (Fapemig) e ao Conselho Nacional de Desenvolvimento Científico e Tecnológico (CNPq) pelo auxílio financeiro que permite o desenvolvimento desta pesquisa.
}

DADOS - Revista de Ciências Sociais, Rio de Janeiro, vol. 56, no-3, 2013, pp. 497 a 530. 
inquietações iniciais da variação da desigualdade de renda sob uma perspectiva temporal da história brasileira, da variação da sua magnitude entre os estados brasileiros e de sua variância entre os estados no que se refere aos seus determinantes. Acredito que as diferentes histórias políticas dos estados brasileiros formatam a natureza dos partidos e o nível de competição política nos estados e este sistema político influencia na implementação de políticas públicas e suas respectivas arenas.

Em geral, a literatura sugere que a desigualdade de renda é determinada pela heterogeneidade da força de trabalho e concorda que esta é determinada por fatores tais como idade, sexo, região de residência e, principalmente, pelo nível educacional (Langoni, 1973; Ramos e Vieira, 2001; Ferreira et al., 2007). No início deste debate, Fishlow (1972) defendeu a importância das políticas tanto fiscais e econômicas, quanto sociais e educacionais como determinantes do aumento da desigualdade naquele momento. Para o autor, o incremento real da desigualdade foi consequência de escolhas políticas daquele período. É nesta linha que nosso argumento é construído: ora, se as políticas sociais, entre elas as educacionais, são determinadas por fatores político-institucionais tais como ideologia, competição política, legado, restrições e características institucionais (Castles, 1982; Chhibber e Nooruddin, 2004; Hicks e Swank, 1992), então, é razoável a hipótese de que a desigualdade de renda é, sim, determinada por fatores políticos, além dos econômicos. Estes, tanto quanto aqueles, são escolhas governamentais (Bradley et al., 2003; Kenwothy e Pontusson, 2005; Iversen e Soskice, 2006).

Este trabalho visa analisar o impacto do arcabouço político-institucional dos estados brasileiros sobre a execução de políticas utilizando-se a desigualdade de renda como indicador das escolhas de alocações de gastos diferenciados. Ou seja, será analisado como as características do sistema partidário, dos níveis de competição político-eleitoral e das políticas prévias (legado), que definem regras de competição e processos políticos, também no nível estadual, impactam na distribuição de renda desse mesmo ente federativo.

O primeiro questionamento metodológico ao se querer estudar a desigualdade de renda utilizando os estados da federação como unidade de análise advém do fato de que a maior parte das políticas redistributivas ou das políticas econômicas que afetam diretamente o mercado 
de trabalho são de responsabilidade do governo federal e, portanto, os estados não teriam ingerência no escopo da arena redistributiva. A resposta para isto é uma outra pergunta: se a redistribuição de renda depende de políticas do nível central de governo, o que explica tanta heterogeneidade na evolução da desigualdade entre os estados? Acreditamos que existem características políticas e institucionais que determinam o solo mais ou menos fértil para políticas redistributivas, isto é, os esforços de políticas refletem as características dos governos estaduais, além das políticas prévias que também são resultados de escolhas políticas passadas. Os governos empreendem diferentes esforços políticos traduzidos em políticas mais ou menos distributivas que, por meio de diferentes mecanismos, impactam na redistribuição de renda dos estados.

Para alcançar os objetivos aqui propostos dividiremos o trabalho em cinco partes, além desta introdução. Na primeira, será explorada a variação do fenômeno em análise tanto no tempo quanto entre os estados, como, ainda, em sua composição. Na segunda seção mostraremos como a literatura vem inserindo a análise do impacto dos fatores político-institucionais na desigualdade de renda em sua agenda. Neste caso, o objetivo é ver quais são os indicadores utilizados, as hipóteses testadas e as metodologias em uso. Depois serão apresentados mecanismos causais e as hipóteses a serem testadas. Na quarta seção será apresentada a metodologia utilizada e os modelos analisados. Por fim, são apresentados os resultados e tecidas as considerações finais mostrando que os partidos apresentam diferentes investimentos em políticas redistributivas mesmo diante dos constrangimentos institucionais impostos pelo governo central. Isto é, não somente as políticas advindas do governo federal, mas as características políticas dos estados influenciam também nos níveis de desigualdade de renda.

\section{VARIAÇÃO DA DESIGUALDADE DE RENDA}

Antes de mostrar as bases teórico-analíticas do trabalho veremos a variabilidade da desigualdade de renda no tempo e entre os estados. A evolução da desigualdade no Brasil nas últimas três décadas é mostrada no Gráfico 1 por meio de quatro indicadores: o índice de Gini, o Índice de Theil-T, a razão de renda entre os $10 \%$ mais ricos e os $40 \%$ mais pobres, e a razão 20/20 (Soares, 2006). Observa-se que na segunda metade da década de 1970 (governo Ernesto Geisel) a desigualdade atingiu níveis muito altos. Em seguida há uma tendência de queda, 


\section{Gráfico 1}

Medida de Desigualdade de Renda (1976-2004)

Painel $1-T$ de Theil e Gini

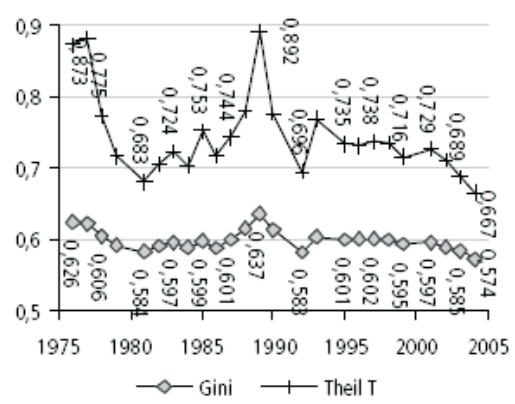

Painel 2 - Razōes $10 / 40$ e $20 / 20$

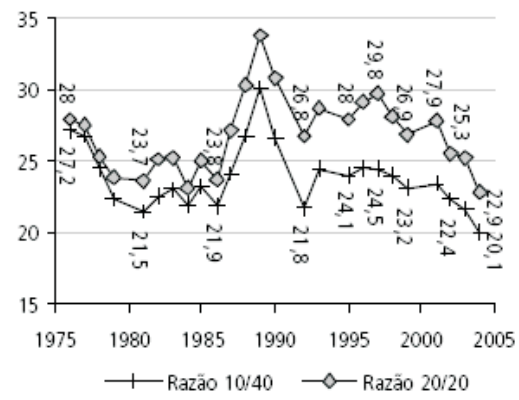

Fonte: Soares (2006 apud Barros et al., 2003).

mas em 1986, período da hiperinflação ${ }^{1}$, começa a subir novamente, atingindo um pico ao final da década de 80. Note-se que o ano de 2004 apresenta os menores valores da desigualdade, para qualquer dos indicadores, na série temporal aqui considerada.

Em segundo lugar, vamos observar a variação da desigualdade de renda entre os estados. O Gráfico 2 mostra os Índices de Gini de todos os estados, mais o Distrito Federal, para o ano de 2008. Observam-se diferentes padrões regionais, sendo que, como esperado, os estados da região Sul apresentam indicadores abaixo da média nacional $(0,553)$ e os estados nordestinos os maiores índices do conjunto. Destacam-se os altos índices de desigualdade do Distrito Federal, Paraíba e Alagoas. É importante ressaltar as diferenças de desigualdade apresentada pelos estados brasileiros. A variação apresenta desde valores mais baixos como os do Amapá $(0,451)$ e Santa Catarina $(0,465)$ que se comparam ao México $(0,461$ em 2004), até o outro extremo que é o caso do Distrito Federal com 0,622, que se compara a Serra Leoa $(62,9)$.

Para os propósitos deste trabalho é importante também termos ideia dos diferentes padrões de comportamento da desigualdade de renda no tempo entre os estados. Para ilustrar o objeto de análise, o Gráfico 3 oferece dois painéis: um que mostra a variação em Alagoas, outro a variação em Minas Gerais; eles mostram a evolução temporal da desigualdade de renda dentro dos dois estados. Observando os painéis pode-se ter ideia do que é possível encontrar no tempo entre os estados padrões muito distintos, e é esta variabilidade que nos interessa aqui. 
Gráfico 2

Índice de Gini segundo Unidades da Federação (2008)

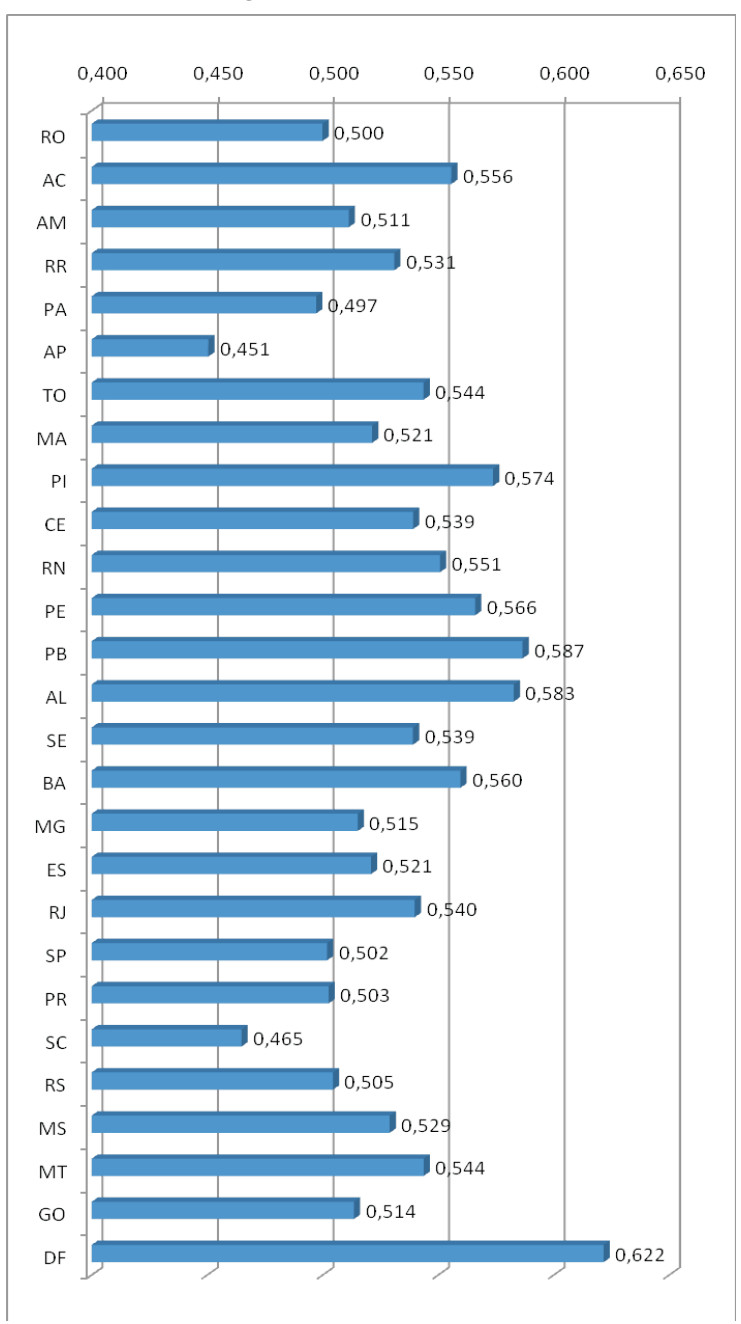

Fonte: Elaboração própria com base nos dados do Ipeadata.

Dado que a variedade do fenômeno de interesse foi aqui demonstrada, justifica-se a análise do impacto do arcabouço político-institucional dos estados brasileiros sobre a execução de políticas. Em trabalho anterior (Sátyro, 2008) mostrei que, diante de constrangimentos institucionais, os partidos políticos perderam sua capacidade explicativa de esforços diferenciados em políticas sociais nos estados brasileiros, isto é, as restrições institucionais impostas pelas políticas restritivas do governo Fernando Henrique Cardoso homogeneizaram os gastos sociais 
Natália Guimarães Duarte Sátyro

\section{Gráfico 3}

Índice de Gini para Alagoas e Minas Gerais (1981-2008)

\section{Painel 1 - Alagoas}

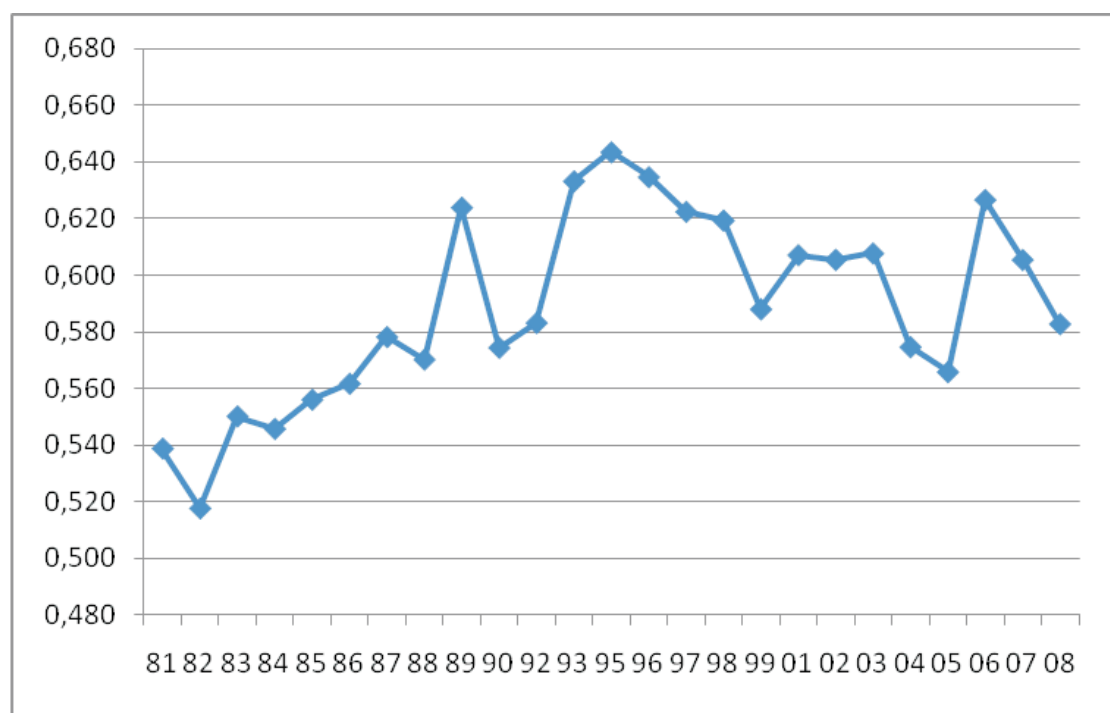

\section{Painel 2 - Minas Gerais}

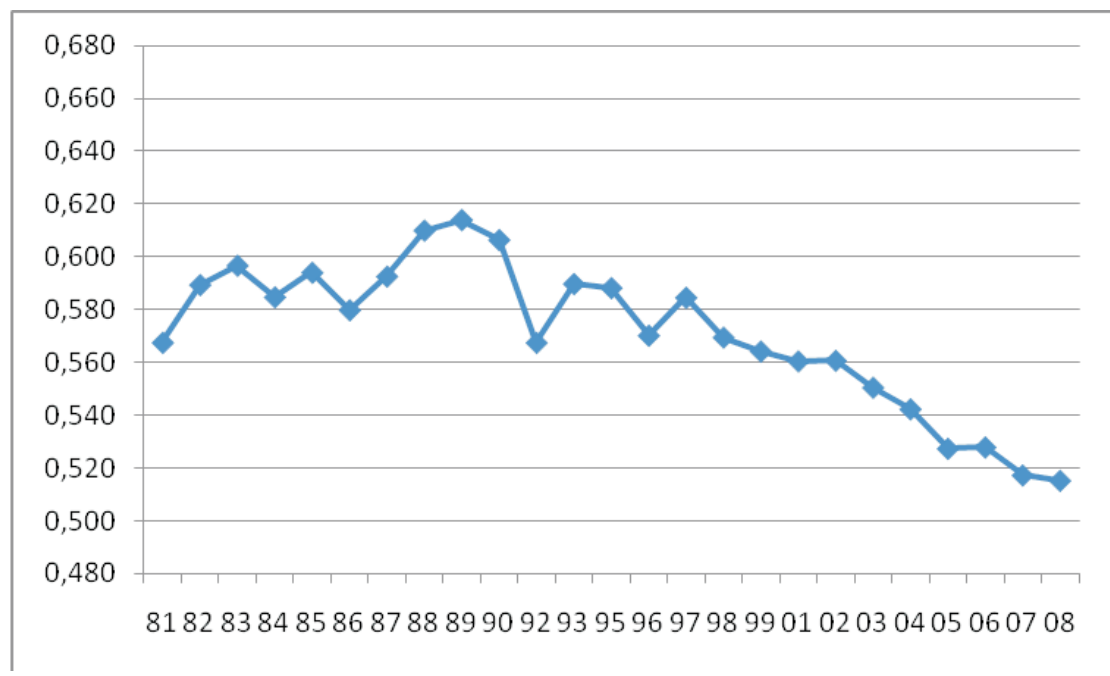

Fonte: Elaboração própria com base nos dados do Ipeadata.

nos estados da federação. Ficou a pergunta de como, então, os partidos fazem diferença na política estadual. Com o intuito de contribuir para esta investigação, este trabalho usará a distribuição de renda como 
proxy de resultados de políticas sociais e de mercado de trabalho. Se o gasto sofreu restrições, houve diferença na qualidade do gasto? Serão utilizadas variáveis que sirvam como proxy de capital humano, de características e condições do mercado de trabalho, e, obviamente - o foco deste trabalho -, das características do sistema político de cada estado. Por este arcabouço político-institucional entende-se as características do sistema partidário, dos níveis de competição político-eleitoral e do legado, que definem como as arenas lowianas são instituídas nos estados e como as políticas são decididas (Sátyro, 2008; Ribeiro, 2005; Lowi, 1964 e 1972).

\section{INSTITUIÇÕES POLÍTICAS E DESIGUALDADE DE RENDA}

Os estudos que visam explicar a variância da distribuição de renda entre países e seus determinantes utilizam indicadores econômicos, institucionais e socioculturais em suas análises. Entretanto, como observam Bradley et al. (2003), ainda há relativamente pouca produção que, ao tratar do tema da desigualdade, dê ênfase aos fatores políticos, aspecto este recentemente apontado também por Kenworthy e Pontusson (2005).

Aqui serão apresentadas breves resenhas de trabalhos comparativos entre países e de análises da desigualdade no Brasil com o intuito de dar uma visão panorâmica do tipo de produção da área. A intenção é modesta, visa mostrar alguns trabalhos que, no conjunto, reflitam minimamente o estado da arte, destacando as diferentes medidas utilizadas como variáveis dependentes, as hipóteses testadas, bem como as técnicas analíticas utilizadas. Depois disto serão expostas as hipóteses que constituem a pretensão deste trabalho e, posteriormente, o modelo proposto.

Bradley et al. (2003) utilizam um painel desbalanceado para analisar os processos de distribuição e redistribuição de renda em 18 democracias pós-industriais do final da década de 70 até o final da década de 90 . Os autores analisam três variáveis dependentes: o Índice de Gini antes e depois das taxas e das transferências (o que denominam de Pre and Post Tax and Transfer Inequality) e a redução na desigualdade medida por meio da proporção dessa redução. Eles investigaram em que medida distribuição de renda e redução de desigualdade são determinadas por diferentes combinações das instituições do mercado de trabalho medidas como densidade de sindicalização e centralização das negoci- 
ações salariais, das condições do mercado de trabalho - utilizando-se a taxa de desemprego, de macroestruturas econômicas, como o pós-industrialismo, e, por fim, das configurações do arcabouço político como presença de governo de esquerda ou de governo democrata cristão. Seus resultados confirmam fortemente suas hipóteses: tanto as variáveis políticas quanto aquelas relacionadas ao mercado de trabalho determinaram a desigualdade de renda nos países analisados.

A conclusões diferentes chegam Scheve e Stasavage (2009) ao analisarem dados para 13 países da Organização para a Cooperação e Desenvolvimento Econômico (OCDE) entre 1916 a 2000, mediante, também, do uso de análise de painel. Neste caso, a análise mais detida e com o foco nas variáveis políticas se dá para o período entre 1976 a 2000, ou seja, os autores diferenciam um pouco os períodos e o tipo de análise empreendida. As principais hipóteses trabalhadas foram: i) governos de esquerda devem ser mais associados a menores desigualdades de renda, dado que estes são mais propensos a políticas redistributivas; ii) arranjos institucionais que garantem centralização de negociação salarial reduzem desigualdade; iii) grau de sindicalização reduz desigualdade; e iv) sistemas proporcionais contribuem tanto para aumentar a centralização das negociações salariais quanto para aumentar a presença de partidos de esquerda. Logo, estas características do jogo eleitoral devem estar associadas a níveis mais baixos de desigualdade.

Os autores utilizam três variáveis dependentes: renda concentrada no $1 \%$ mais rico da população (top 1), renda concentrada nos $10 \%$ mais ricos da população (top 10) e os $10 \%$ menos o $1 \%$ (top 10-1), ou seja, aqueles incluídos entre o percentil 90 e o percentil 99 da distribuição de renda. Entretanto, Scheve e Stasavage sugerem que centralidade da negociação salarial, governo de esquerda e sistema proporcional não são determinantes de desigualdade de renda entre 1976-2000 nos países analisados. Os resultados desses autores levam à conclusão de que crises econômicas e experiências de pós-guerra são mais importantes para se entender a evolução da desigualdade nestes países do que suas características partidárias ou institucionais. Em suas próprias palavras: "nós encontramos pouca evidência de que estes fatores determinem a variação na desigualdade ao longo do tempo, particularmente quando controlamos pelos efeitos não observados dos países (efeito fixo) e pelos efeitos de tempo" (Scheve e Stasavage, 2009:36; tradução minha). 
No Brasil, há também muitos trabalhos que analisam a evolução da desigualdade e, nos últimos anos, muitos deles tentam explicar a sua recente queda, que caracteriza um momento histórico em nossa sociedade. Foi frutífero para a área o debate gerado entre, de um lado, Fishlow (1972), que defendeu que as políticas públicas determinavam o alto nível de desigualdade de renda registrado na década de 60, sugerindo fortemente o papel determinante das escolhas político-governamentais para aquele padrão e, de outro lado, Langoni (1973), com sua defesa da variação do nível educacional como determinante da variação da produtividade da mão de obra. Atualmente, há uma abundante produção sobre a diminuição da desigualdade de renda no Brasil nesta última década, não obstante, com variadas ênfases. Alguns autores enfatizam a relação entre crescimento econômico, ou mesmo instabilidade macroeconômica, e desigualdade de renda (Salm, 2007; Dedecca, 2007; Ferreira et al., 2007); outros, o papel do salário mínimo na distribuição de renda (Salm, 2007; Dedecca, 2007; Giambiagi e Franco, 2007); uns o mercado de trabalho; e ainda outros enfatizam o papel das transferências de renda governamentais como o Programa Bolsa Família e o Benefício de Prestação Continuada (BPC/LOAS, como Soares et al. (2006), Soares et al. (2007), Hoffmann (2007), e Barros et al. (2007). Há aqueles que enfatizam o papel de aspectos educacionais (Ferreira et al., 2007), e, finalmente, os que tiveram seu foco voltado para a análise da variância em nível estadual (Sátyro e Soares, 2009).

Escolhemos dois autores que analisam a evolução da desigualdade no país em um interregno maior de tempo: um, focando o papel do mercado de trabalho e das transferências de renda na conformação da desigualdade, comparativamente, e, outro, que também tenta mostrar os principais determinantes desse processo utilizando conceitos de capital humano. Em trabalho sobre a evolução da desigualdade de renda no Brasil entre 1976 e 2004, Soares (2006) mostra que 2004 foi o ano com a menor desigualdade nas últimas três décadas para quaisquer das quatro medidas utilizadas: Índice de Gini, Índice de Theil-T, razão entre a renda dos $10 \%$ mais ricos e os $40 \%$ mais pobres, e a razão entre a renda dos 20\% mais ricos e os $20 \%$ mais pobres. Mediante análise de decomposição dinâmica de renda, Soares (2006) chega a resultados que mostram que programas de transferência de renda, como o Programa Bolsa Família e o Benefício de Prestação Continuada, são responsáveis por um quarto da queda da desigualdade entre 1995 e 2004. Entretanto, afirma o autor, apesar disso, os rendimentos do trabalho são responsáveis por três quartos dessa queda. Ou seja, para Soares, não resta 
dúvidas de que foi o mercado de trabalho o grande responsável pela desconcentração de renda observada entre os anos de 2001 e 2004, mas reconhece o importante papel relativo das transferências de renda. A importância dada ao papel das transferências de renda é função do baixo custo relativo que estas tiveram no alcance de resultados tão significativos na redução da desigualdade de renda. Esta conclusão é compartilhada por outros autores como Soares et al. (2006), Soares et al. (2007), Hoffmann (2007) e Barros et al. (2007). Com base nessas análises, pode-se afirmar que existem três rendas que promovem igualdade no Brasil: de um lado, as rendas das aposentadorias e pensões indexadas a um salário mínimo, ou seja, o Regime Geral de Previdência Social e, de outro lado, as transferências de renda governamentais - Bolsa Família e Benefício de Prestação Continuada. Destaque-se que todas as três são transferências de renda governamentais. A renda do trabalho, as aposentadorias e pensões e as rendas advindas de capital e outras transferências privadas geram desigualdade em níveis distintos.

Ramos e Vieira (2001) analisam a evolução da desigualdade de renda no Brasil com foco nas décadas de 80 e 90 identificando os principais determinantes do que eles denominam de assimetria da estrutura de rendimentos no mercado de trabalho. Os autores também utilizam decomposição dinâmica de renda dividindo a análise em vários grupos utilizando a idade, o nível educacional, a posição na ocupação, a região geográfica, o setor de atividade além de gênero e cor como determinantes da desigualdade. Ramos e Vieira sugerem fortemente que o principal responsável pela desigualdade de rendimentos no período analisado foi a heterogeneidade dos trabalhadores, principalmente no que concerne à distribuição da escolaridade, visão que também está posta no trabalho clássico de Langoni (1973). Em suas conclusões, Ramos e Vieira também sugerem que a forma de inserção do trabalhador no mercado de trabalho é um fator importante. Ou seja, não negam os achados de Sergei Soares, mas, sim, qualificam seus resultados. O que é importante destacar aqui é que todos esses autores enfatizam que tanto as transferências de renda anteriormente citadas, quanto a distribuição de escolaridade aqui destacada são resultados de esforços de políticas (esforços políticos). Seja nos níveis municipal, estadual ou federal, estamos falando da agenda decisional de governos. Entretanto, como se trata de autores economistas, não há ênfase nos aspectos políticos determinantes diretos e indiretos da desigualdade de renda.

Por meio da análise desta literatura pode-se afirmar que, no âmbito internacional, os especialistas têm se esmerado em explicar a desigual- 
dade, incluindo os efeitos das instituições políticas na redistribuição de renda. Entretanto, no Brasil ainda há uma completa ausência de estudos que enfatizem os aspectos políticos que determinam distribuição de renda e, menos foco ainda há nesse tema com o recorte nas unidades subnacionais. O que se destaca é que há nos estudos brasileiros uma variação substantiva das medidas utilizadas como variáveis dependentes. Apesar disto, de acordo com Barros et al. (2007:89), os autores concordam "quanto ao fato de a distribuição de renda de 2005 apresentar uma relação de dominância de Lorenz sobre a de 2001[o que] significa que, qualquer que seja a medida de desigualdade utilizada, a desigualdade de renda é menor em 2005 do que em 2001 e, portanto, a queda observada independe da medida escolhida para aferi-la". Por outro lado, para os objetivos deste trabalho destaca-se que naqueles que enfatizam os fatores políticos, os resultados relativos aos indicadores políticos são bastante divergentes. Isto reforça ainda mais a necessidade de aprofundamento do tema, em especial no Brasil, para saber a importância da política nesse processo de diminuição da desigualdade de renda.

A isto se soma o fato de que esse material que enfatiza os aspectos políticos contém duas limitações para o desenvolvimento do conhecimento nessa temática: a primeira, que é um viés de seleção de países desenvolvidos sobre os quais se desenvolve a teoria em função de um problema estrutural que é a disponibilidade de dados; a segunda limitação advém da primeira: uma vez que as análises concentram-se em países desenvolvidos, algumas hipóteses construídas e testadas são baseadas em um mercado de trabalho mais homogêneo e amplo. Esses países em geral associaram crescimento econômico e desenvolvimento social, configurando uma sociedade salarial com generalização da proteção social (Boschetti, 2006). A média do Índice de Gini para os países analisados no período gira em torno de 0,3 , ou seja, realidades muito distintas de países em desenvolvimento, como é o caso do Brasil.

Aqui há um problema: temos de saber se esse modelo analítico é generalizável, ou seja, se consegue explicar aquelas sociedades que não conseguiram consolidar um mercado de trabalho, ou, em outras palavras, onde o mercado de trabalho é precário, heterogêneo e com altos índices de subemprego, com altas taxas de desemprego e com um grau de informalidade altíssimo como o nosso. A teoria explicaria os resultados daqueles países que até conseguiram alcançar relativo crescimento econômico, mas este não foi traduzido em repartição dos frutos 
da expansão econômica? Ou seja, é preciso analisar se esta é realmente uma teoria abrangente que se aplica a países onde não houve garantia de proteção social generalizada, não houve manutenção de grandes equilíbrios na condução da economia e onde a condição salarial é frágil ou ausente para grande parte da população e, portanto, são sociedades altamente desiguais, como é o caso brasileiro (Boschetti, 2006).

Apesar desses problemas, a revisão dessa literatura nos permite sustentar a importância dos fatores políticos e institucionais na redistribuição de renda no nível nacional. Vimos como tanto as instituições do mercado e de trabalho quanto as políticas determinaram os resultados encontrados nos trabalhos aqui analisados. Assim, cabe partir da hipótese clássica de que a presença de partidos mais à esquerda do espectro ideológico aumenta os gastos sociais. Os estudos analisados acima mostram que eles também tenderão a elaborar políticas mais redistributivas do que partidos mais conservadores (Iversen e Soskice, 2006; Bradley et al., 2003; Pontusson, Rueda e Way, 2002), seja pelo investimento naquelas políticas que aumentam o capital humano (Fishlow, 1972), ou ao retrair os altos salários, impulsionando, em termos relativos, os menos qualificados e mal remunerados (Pontusson, Rueda e Way, 2002), ou mesmo que indiretamente, como afirmam Iversen e Soskice (2006).

As políticas de cunho redistributivo que possuem mais alcance são elaboradas no âmbito federal de governo, tendo forte impacto nas contas nacionais, na estabilidade econômica e na conformação do mercado de trabalho são as macropolíticas econômicas, decisões centralizadas em nossa federação. Não há como discordar que o nível central de governo ainda é preponderante. Por exemplo, mesmo com todo o processo de descentralização das políticas educacionais disparado a partir de determinações constitucionais, este ocorre sob a coordenação da União, ou seja, também é papel do governo central determinar as diretrizes educacionais ${ }^{2}$.

Dada essas ponderações, o questionamento deste artigo fica ainda mais proeminente: se as diretrizes para políticas redistributivas são criadas pelo nível central de governo; se é no plano nacional que se formulam as macropolíticas que conformam o mercado de trabalho, então, o que explica a enorme variedade de padrões da evolução da desigualdade encontrada tanto no tempo, em cada estado, quanto entre os estados? Por que alguns estados redistribuem mais que outros? Argu- 
mentamos que a riqueza de um trabalho comparativo entre unidades federativas subnacionais está na possibilidade de um desenho de pesquisa que viabilize uma interpretação mais precisa dos resultados empíricos, ou que abra uma agenda de pesquisa para aprofundamento da investigação, uma vez que esses fatores institucionais, tais como federalismo, características do sistema eleitoral, e bicameralismo - que variam entre países - estarão controlados (Gupta e Damania, 2004; Chhibber e Nooruddin, 2004).

Como a nossa unidade de análise são os estados, a relação que procuramos entre a política e a desigualdade de renda é tanto direta quanto indireta. Existem dois mecanismos através dos quais os fatores políticos no nível estadual afetarão a redistribuição de renda: 1) eles a influenciarão por meio das políticas educacionais que conformarão o capital humano, políticas estas que, apesar de receberem diretrizes do governo federal, são de responsabilidade dos estados e dos municípios; e 2) a influenciarão por meio de políticas que afetem diretamente o mercado de trabalho; neste caso, há uma variação considerável entre os estados pela adesão e pelos esforços empreendidos em políticas de qualificação profissional para o mercado de trabalho. Partimos da premissa de que as diferenças de salário são provenientes da heterogeneidade dos trabalhadores no que se refere aos seus atributos produtivos, entre os quais a educação formal e a educação profissional que atuam como atenuantes ou amplificadoras da dispersão salarial (Ramos e Vieira, 2001; Ferreira et al., 2007). Ramos e Vieira (2001:8) concluem em seu trabalho que, "dentre as causas de dispersão salarial investigadas, a heterogeneidade dos trabalhadores, principalmente em termos de escolaridade, é aquela que se sobressai como o principal fator responsável pela desigualdade de rendimentos em todos os anos analisados".

Para reforçar seu argumento, Ramos e Vieira mostram os resultados de pesquisas relativas a vários países com a mesma abordagem expondo a contribuição da educação para a desigualdade de renda em cada um desses países: Argentina, Brasil, Colômbia, Costa Rica, México, Peru, Uruguai, Venezuela e América Latina em geral. Os autores mostram que, com exceção do Uruguai e da Argentina, a educação se apresenta como fator de peso na distribuição de renda (ibidem: 9).

Para além da educação formal, trabalhamos com a hipótese de que o aumento do investimento em políticas de qualificação profissional está diretamente associado ao crescimento ou diminuição da econo- 
mia informal. O mercado de trabalho informal é aquele que comporta um "tipo de inserção, notadamente sob a forma de assalariamento sem carteira de trabalho assinada", e é também "onde prevalecem os trabalhadores jovens com um baixo nível de instrução e, portanto, em alguma medida seus menores rendimentos são explicados por esses fatores (além do fato de que a economia informal tende a ser mais importante nas regiões geográficas mais pobres)" (ibidem:8). Complementarmente, Cêa sugere que a qualificação profissional faz parte das políticas de geração de emprego por meio de uma "estratégia de qualificação em massa da força de trabalho, com vistas ao desenvolvimento de competências e habilidades para ampliação das condições de empregabilidade dos trabalhadores" (Cêa, 2006:2). Como informa a autora, "de 1995 a 2003, o governo brasileiro, por meio do Ministério do Trabalho e Emprego (MTE), implementou uma política de formação, em massa, da mão de obra brasileira, por meio da execução do Plano Nacional de Qualificação do Trabalhador (Planfor)" que, com a chegada do presidente Lula ao poder, em 2003, foi substituída pelo Plano Nacional de Qualificação (PNQ) (ibidem:1). Para se ter a dimensão do alcance dessas ações, de acordo com Cêa, entre 1995 e 2002 cerca de 20,7 milhões de trabalhadores foram atingidos por essas políticas (ibidem: 3 ).

Para os fins deste artigo é importante ressaltar que apesar do Planfor ter indicado diretrizes gerais, ele não estabeleceu um formato único para os programas de qualificação e requalificação profissional no âmbito subnacional. Segundo Peixoto (2008), no nível de estados e municípios o Plano se deu por adesão, e os estados, por meio da atuação de suas Secretarias Estaduais de Trabalho ${ }^{3}$ (regulada pela Resolução 126 do Codefat $^{4}$ ) e das Comissões Estaduais de Emprego ${ }^{5}$, tiveram um papel importante na conformação dessas políticas nos âmbitos estadual e municipal. De acordo com esse autor (ibidem:67), "durante esse processo, podemos apontar que as Secretarias Estaduais, à medida que implementavam o Planfor também promoveram mudanças nas ações desenvolvidas, uma vez que se baseavam em seus planos estratégicos de desenvolvimento, fato que significou um processo autônomo de implementação no que tange as principais decisões a serem tomadas, respeitando as diferenças e as necessidades regionais". Entre os trabalhos que são importantes para entender tanto a passagem do Planfor para o PNQ quanto suas diferenças no nível estadual, há dois que se destacam: uma análise comparativa sobre esses planos realizada por Peixoto (2008) em sua dissertação, e a tese de Almeida (2003), que analisa as políticas governamentais de educação profissional no Brasil. Os resul- 
tados desses trabalhos reforçam o argumento deste artigo de que o espaço de atuação dos governos estaduais na promoção de políticas relativas à qualificação profissional e à geração de trabalho e renda é primordial para a conformação do mercado de trabalho. Ainda que fique a possibilidade de este tipo de ação reforçar mais a ideia relacionada ao capital humano, ela está voltada para o mercado de trabalho; a maior parte de seu público compõe um segmento populacional com níveis mais baixos de capital humano. Desta forma, apesar de a ação estar incrementando o capital humano, o faz sob o aspecto específico das necessidades deste segmento de inserção no mercado, ou seja, é apenas uma das dimensões do conceito de capital humano. E é aí que o papel do Estado, como elaborador e gestor dessa política, pode fazer, e faz, investimentos diferenciados entre si com vistas a aumentar as chances deste segmento de melhor inserção no mercado.

Este artigo sustenta, ainda, com base nos trabalhos sobre governança regional e, mais especificamente sobre reestruturação produtiva regional, que o Estado é um ator central na coordenação para investimento produtivo de determinadas regiões como as metropolitanas, onde existem muitas externalidades espaciais e bens públicos. Há uma série de questões determinantes para atração de investimento privado que demandam coordenação de interesses de municípios diversos, espaço esse que pode ser ocupado pelos governos estaduais. A citação de Klink e Lépore (2002) ilustra nosso ponto:

[...] as questões relacionadas com o uso e ocupação do solo e o desenvolvimento de cadeias produtivas competitivas representam temas, cujo limite geográfico extrapola e transborda os limites administrativos de cada cidade. Da mesma forma, a segurança pública, as bacias hidrográficas limpas e baratas e a presença de um conjunto de redes urbanas técnicas (água, saneamento, transporte) têm características nítidas de bens públicos com elementos de indivisibilidade e não-exclusividade. À medida que crescem a frequência dessas externalidades espaciais e a presença potencial de bens públicos, podemos inferir que aumenta a demanda por uma ação coordenada que não pode ser equacionada pelos mecanismos de mercado. Portanto, mais particularmente nas regiões metropolitanas e nas cidades-região com maior densidade populacional e complexidade das cadeias produtivas, presenciamos o surgimento de uma agenda estratégica em torno dos temas de cooperação, ação coletiva e mobilização produtiva de atores públicos e privados. 
Analisando os limites e potencialidades de novos arranjos institucionais das regiões metropolitanas e regionais a partir do caso do ABC paulista, os autores mostram que, em alguns temas, há uma variação na forma como os governos estaduais lidam com determinadas questões, seja no âmbito de seus Executivos ou em seus Legislativos. Ressaltam também a variação estadual em diversas matérias mostrando que algumas constituições estaduais variam na regulamentação de algumas delas, umas avançando, outras tratando de forma genérica, outras omitindo simplesmente (Klink e Lépore, 2002). A intenção aqui é mostrar espaços de ação dos governos estaduais que afetam o mercado de trabalho, seja de forma direta ou indireta, como já exposto.

Assim, vemos que há dois mecanismos através dos quais a política estadual de governo determina os níveis de desigualdade de renda. O diagrama abaixo ilustra os mecanismos causais por meio dos quais os fatores políticos influenciam a política educacional e o grau de informalidade do mercado de trabalho, impactando assim nos níveis de desigualdade de renda nos estados.

Resumindo, observa-se no diagrama a seguir que surgem dois caminhos por meio dos quais o arcabouço político-institucional dos estados afetará a desigualdade de renda: tanto pela promoção de capital humano, isto é, investimento em educação, quanto pelo investimento em políticas de qualificação profissional, ou mesmo políticas que possibili-

Diagrama 1

Diagrama de Path Analysis que Representa a Estrutura do Modelo Analítico

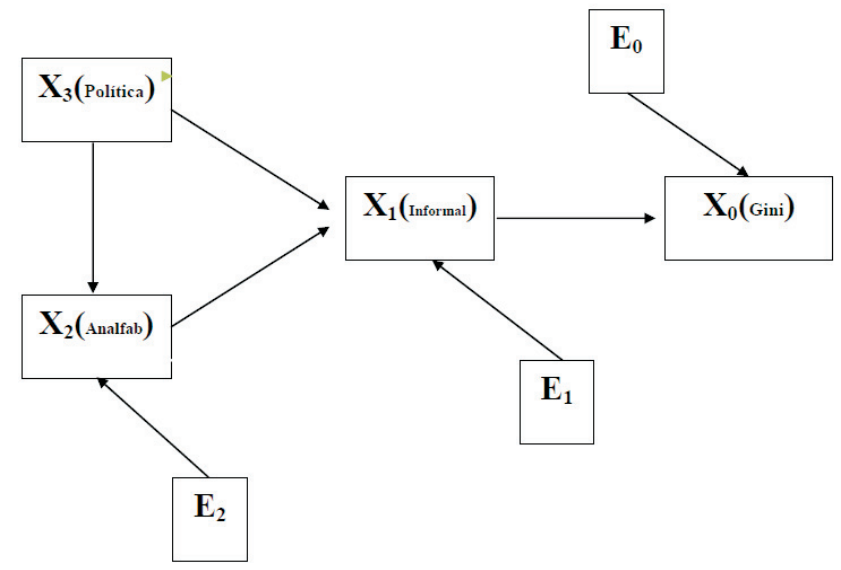

Fonte: Elaboração própria. 
tem tornar espaços regionais mais atrativos ao investimento privado. Dessa forma, pressupõe-se que o sistema partidário, bem como o nível de competição política nos estados, irá afetar tanto a formação de capital humano (indicado aqui pela taxa de analfabetismo), quanto as características do mercado de trabalho tais como a precariedade dos postos de trabalho, o nível de emprego e o grau de informalidade (indicadas aqui pelo grau de informalidade). Pressupõe-se também que o capital humano impactará diretamente a produtividade da população que determinará a qualidade da inserção no mercado de trabalho.

A proposta deste artigo é analisar a hipótese de que o desenvolvimento (redução ou aumento) da desigualdade, isto é, as diferenças nos padrões de redistribuição de renda, serão determinadas, também no nível subnacional, pela combinação de diferentes fatores. Dito de outra maneira, o arcabouço político e institucional determina a redistribuição de renda e a redução na desigualdade direta e indiretamente em função do nível do estado de bem-estar implantado por meio de políticas redistributivas (Bradley et al., 2003; Kenwothy e Pontusson, 2005). As hipóteses que daí derivam são clássicas: partidos mais à esquerda do espectro ideológico tendem a colocar mais esforços na realização de políticas redistributivas do que partidos à direita; arenas políticas competitivas promovem mais esforços tanto na realização de políticas sociais quanto de políticas redistributivas, ou seja, ambientes com competição eleitoral apresentam níveis de incerteza maior para as elites partidárias.

Contudo, esse argumento tem se mostrado controverso. Há uma literatura recente com foco tanto na explicação do surgimento e o perfil da esquerda na América Latina quanto em mostrar as reformas e políticas implementadas tendendo claramente por princípios universalistas e redistributivos. Essa discussão defende que crises governamentais com a direita no poder, problemas econômicos domésticos e fatores estruturais como desigualdade de renda, altos índices de informalidade e de precariedade dos postos de trabalho e suas consequências na diminuição da qualidade de vida de maneira generalizada têm gerado um suporte para a esquerda (Levitsky e Roberts, 2011; Blanco e Grier, 2011; Barrett, Chávez e Garavito, 2008). Ou seja, a esquerda ascende porque as condições de vida não estão boas, porque há desigualdade e porque esta situação pode ser entendida como um legado das políticas neoliberais precedentes. Transpondo para a realidade brasileira, é possível considerar a proposta de que nos últimos anos a esquerda conse- 
guiu ascender em alguns estados por causa das precedentes condições adversas e, portanto, poderá apresentar resultados piores, uma vez que partiu de patamares mais altos de pobreza e desigualdade. Por fim, consideramos que o legado é muito importante para o entendimento da distribuição de renda e aqui ele estaria operando em dois lugares: por um lado, quanto mais foi investido em educação em governos anteriores, maior o nível atual de capital humano no presente; por outro lado, podemos argumentar que a política (ou "política prévia") pode definir o poder político por meio da definição da agenda pública, padrões de conflito entre grupos de interesse, influência ou mudança nas regras formais, definição prévia de alocação de recursos com maior ou menor capacidade incremental.

\section{METODOLOGIA E MODELOS}

O questionamento deste trabalho é compartilhado por Bradley et al. quando sugerem que, dada a importância do entendimento do grau de influência que os fatores políticos e institucionais têm sobre a desigualdade, é de se estranhar que só muito recentemente a comunidade acadêmica começasse a se interessar efetivamente pelo assunto. De acordo com os autores, a justificativa com certeza é mais estrutural do que relativa a interesses, uma vez que até pouco tempo atrás os dados disponíveis não permitiam muitas inferências (Bradley et al., 2003).

Cabe aqui, uma explicação do uso do Índice de Gini como indicador de desigualdade de renda, nossa variável dependente. Boa parte da literatura internacional sobre desigualdade de renda utiliza Pre tax and transfer gini index of income inequality among households e Post tax and transfer gini index of income inequality among households. Estas medidas são constituídas a partir do Índice de Gini, respectivamente descontando-se as taxas e as transferências (antes e depois delas), o que dá uma medida mais fidedigna da real alteração na redistribuição isolando taxas e transferências de pensionistas, por exemplo. Entretanto, no Brasil o nível de desagregação dos dados sobre desigualdade de renda não permitem a extração das taxas e das transferências como os dados oriundos do Luxembourg Income Survey (LIS), que permitem acesso aos microdados e, portanto, possibilitam recalcular e remover distorções na distribuição de renda. Isto implica que a crítica feita por Bradley et al. (2003) ainda persiste para países como o Brasil na medida em que os dados disponíveis nos restringem à análise ao uso do Índice 
de Gini. Ou seja, atualmente não é possível realizar estudos dessa natureza sem as distorções impostas pelos dados.

A pesquisa visa analisar dados das gestões dos governos estaduais entre 1992 e 2006, momento subsequente à redemocratização ${ }^{6}$, o que nos dá um período de 15 anos. Para análise de estruturação de políticas nacionais esse pode ser um recorte considerado curto, mas para o impacto de algumas políticas redistributivas já é suficiente, na medida em que, como vimos na segunda seção deste trabalho, há tanto uma queda do Índice de Gini no âmbito nacional nos últimos anos, quanto variação temporal, com tendências distintas, entre os estados brasileiros nesse mesmo recorte temporal. Este período trabalhado permite também a consideração do processo de descentralização fiscal de atribuições, competências e recursos para execução de políticas entre os entes federados dadas pela Constituição de 1988. A Constituição foi um ponto de inflexão institucional na medida em que introduz o conceito de Seguridade Social, transforma Assistência Social em política pública, vincula programas e benefícios sociais ao salário mínimo, determina a oferta de benefícios não contributivos a grupos necessitados, antes não assistidos, entre outros avanços.

Outro aspecto a ser levantado aqui são as variáveis utilizadas como indicadores dos fatores político-institucionais das hipóteses expostas ao final da seção anterior, mais especificamente, ideologia partidária dos governos estaduais e grau de competição política nas eleições majoritárias, mensurados, respectivamente, pelo partido do governador eleito, incluindo a coligação vencedora e a porcentagem de votos no primeiro turno eleitoral obtidos por aquela coligação. A análise proposta abarcará o equivalente a quatro mandatos dessas unidades federativas. As observações para o cargo de governador, com a presença de 14 partidos diferentes, são divididas da seguinte forma: Partido do Movimento Democrático Brasileiro (PMDB: 23,7\% - 20 mandatos); Partido da Social Democracia Brasileira (PSDB: 22,2\% - 19 mandatos); Partido da Frente Liberal (PFL: 17,5\% - 15 mandatos); Partido dos Trabalhadores (PT: 7,4\% - 6 mandatos); Partido Socialista Brasileiro (PSB: 8,9\%-8 mandatos); Partido Democrático Trabalhista (PDT: 6,2\% - 5 mandatos); Pequenos de direita (Partido Trabalhista Brasileiro - PTB; Partido Progressista Renovador - PPR; Partido Democrático Social - PDS; Partido Progressista Brasileiro - $\mathrm{PPB}^{7}$; Partido Trabalhista Renovador PTR; Partido Social Cristão - PSC; Partido Social Liberal - PSL; Partido Popular Socialista - PPS: 14,2\% - 12 mandatos). 
Na Tabela 1 são mostrados os coeficientes de correlação entre as variáveis explicativas e o Índice de Gini; todos apresentam significância a 1\%.

Tabela 1

Variáveis Explicativas e sua Correlação com o Índice de Gini

\begin{tabular}{|c|c|}
\hline \multicolumn{2}{|l|}{ Competição Política } \\
\hline Porcentagem de votos no primeiro turno & 0,376 \\
\hline \multicolumn{2}{|l|}{ Indicador de precariedade do mercado de trabalho } \\
\hline Grau de informalidade & 0,508 \\
\hline \multicolumn{2}{|l|}{ Indicadores de educacionais } \\
\hline Analfabetos de 15 anos ou mais & 0,676 \\
\hline Frequência escolar de pessoas com 7 a 14 anos de idade & $-0,513$ \\
\hline \multicolumn{2}{|l|}{ Variáveis de controle } \\
\hline Esgoto sanitário & $-0,413$ \\
\hline PIB per capita & $-0,480$ \\
\hline
\end{tabular}

Fonte: Elaboração própria a partir dos dados do extinto Banco de Dados Eleitorais do Brasil (BDEB) e do Ipeadata.

A análise empírica da desigualdade de renda se dará por regressão de série temporal com corte transversal (STCT), uma vez que seu objetivo é uma análise comparativa, sob uma perspectiva intertemporal, do impacto da política, no âmbito estadual, sobre a distribuição de renda. Para conseguir realizar a análise será necessário um método que corrija os erros-padrão em análises de painel e de séries temporais com corte transversal. Desta forma, a análise empírica ora apresentada baseia-se na discussão de Beck e Katz (1995) que sugere a utilização do modelo de regressão Prais-Winsten com panel corrected standard error model (PCSE-AR1), que gera coeficientes mais bem estimados. Este modelo é o mais apropriado também pelo fato de corrigir problemas de heterocedasticidade ${ }^{8}$. Para contemplar o mecanismo causal aqui defendido e apresentado no diagrama 1 serão analisados três modelos PCSE-AR1 que conterão também efeito fixo dos estados e dos anos analisados: um, utilizando a taxa de analfabetismo como variável dependente, indicadora das condições educacionais estaduais e, portanto, de capital humano; outro, utilizando o grau de informalidade do mercado de trabalho como variável dependente; por fim, o terceiro modelo, que terá como variável dependente o Índice de Gini. Segue a formalização dos modelos: 


\section{Modelo 1}

$\gamma_{\text {it }}\left(\right.$ Taxa de analfabetismo -15 anos e mais $\left.{ }_{\text {it }}\right)=\beta_{0 \text { it }}+$

$\beta_{1}$ (Frequência escolar -7 a 14 anos $\left.-(\%)_{\text {it }}\right)+$

PT como partido de referência

$\left.\beta_{2}(P M D B)_{i t}\right)+\beta_{3}\left(P P_{i t}\right)+\beta_{4}\left(P_{i t}\right)+\beta_{5}\left(P_{i t}\right)+\beta_{6}\left(P_{i t} B_{i t}\right)+\beta_{7}(P e-$ quenos Partidos de Direita $\left.{ }_{i t}\right)+\beta_{8}$ (Votos no Primeiro Turno $\left.(\%)_{i t}\right)+$

Variáveis de controle

$\beta_{9}$ (Esgoto sanitário $\left.(\%)_{\text {it }}\right)+$

$\beta_{10}\left(\right.$ PIB per capita $\left.{ }_{\text {it }}\right)+$

Efeito fixo temporal: 1992 como ano de referência

$\beta_{11 \text { a } 22}(1993 \ldots$ 2006) +

$\eta_{\pi \mathrm{i}}+\mu_{\mathrm{it}}$

\section{Modelo 2}

$\gamma_{\text {it }}\left(\right.$ Grau de informalidade $\left.{ }_{i t}\right)=\beta_{0 \text { it }}+$

$\beta_{1}$ (Taxa de analfabetismo -15 anos e mais $\left.{ }_{\text {it }}\right)+$

$\beta_{2}$ (Frequência escolar -7 a 14 anos $\left.-(\%)_{\text {it }}\right)+$

PT como partido de referência

$\left.\beta_{3}(\mathrm{PMDB})_{\mathrm{it}}\right)+\beta_{4}\left(\mathrm{PSDB}_{\mathrm{it}}\right)+\beta_{5}\left(\mathrm{PFL}_{\mathrm{it}}\right)+\beta_{6}\left(\mathrm{PDT}_{\mathrm{it}}\right)+\beta_{7}\left(\mathrm{PSB}_{\mathrm{it}}\right)+\beta_{8}(\mathrm{Pe}-$ quenos Partidos de Direita $\left.{ }_{i t}\right)+$

$\beta_{9}$ (Votos no Primeiro Turno $\left.(\%)_{\mathrm{it}}\right)+$

Variáveis de controle

$\beta_{10}\left(\right.$ Esgoto sanitário $\left.(\%)_{\text {it }}\right)+$

$\beta_{11}\left(\right.$ PIB per capita $\left.a_{\mathrm{it}}\right)+$

Efeito fixo temporal: 1992 como ano de referência

$\beta_{12 \mathrm{a} 23}(1993 \ldots$ 2006) +

$\eta_{\mathrm{i}}+\mu_{\mathrm{it}}$

\section{Modelo 3}

$\gamma_{\text {it }}\left(\right.$ Índice de Gini $\left._{\text {it }}\right)=\beta_{0 \text { it }}+$

$\beta_{1}\left(\right.$ Grau de informalidade $\left.\mathrm{it}_{\mathrm{it}}\right)+$

PT como partido de referência

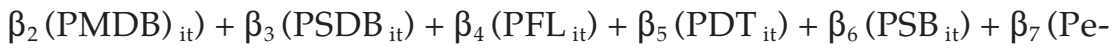
quenos Partidos de Direita $\left.{ }_{i t}\right)+$

$\beta_{8}$ (Votos no Primeiro Turno $\left.(\%)_{\text {it }}\right)+$

DADOS - Revista de Ciências Sociais, Rio de Janeiro, vol. 56, no 3, 2013 
Variáveis de controle

$\beta_{9}$ (Esgoto sanitário $\left.(\%)_{\text {it }}\right)+$

$\beta_{10}\left(\right.$ PIB per capita $\left.{ }_{\mathrm{it}}\right)+$

Efeito fixo temporal: 1992 como ano de referência

$\beta_{11 \text { a } 22}(1993 \ldots$ 2006) +

$\eta_{\mathrm{i}}+\mu_{\mathrm{it}}$

em que $i$ representa os estados, $i=1, \ldots, N$; t os anos,

$\gamma_{\gamma i \mathrm{t}}$ é a variável dependente (Índice de Gini como proxy de desigualdade de renda) relativa ao i-ésimo estado brasileiro no t-ésimo ano,

$\beta_{\text {nit }}$ é o n-ésimo parâmetro associado ao i-ésimo estado brasileiro no t-ésimo ano ou ao intercepto;

em que $\eta_{\mathrm{i}}$ é o efeito não observado de cada estado;

em que $\mu_{\text {it }}$ é o termo de erro que segue um processo de autocorrelação de ordem 1, AR(1), ou seja onde assume-se que $\mu_{\mathrm{it}}$ é heterocedástico e correlacionado entre os painéis.

Na Tabela 2 serão apresentados três modelos, cabe ressaltar que o DF foi excluído dos modelos por apresentar multicolinearidade com grau de informalidade 9 .

\section{OS RESULTADOS}

A análise dos três modelos apresentados permite-nos observar que os mecanismos causais aqui defendidos acontecem na prática, mas a direção dos efeitos deve ainda ser objeto de pesquisa. Como sugerido neste trabalho, as evidências mostram que há um efeito da política realizada no nível estadual tanto com a taxa de analfabetismo, quanto com o grau de informalidade do mercado de trabalho e este, por sua vez, afeta os níveis de desigualdade de renda nos estados. Isto é, confirma-se a hipótese central deste artigo que defende que política estadual impacta na distribuição de renda. Como sugerido, podemos observar que a frequência escolar afeta a taxa de analfabetismo utilizado aqui como indicador da qualidade do capital humano disponível para o mercado. Observamos, em seguida, como a frequência escolar afeta o grau de informalidade do mercado de trabalho, efeito este esperado pela literatura pertinente (Ramos e Vieira, 2001; Ferreira et al., 2007). 
Política Estadual e Desigualdade

Tabela 2

Modelos PCSE-AR1

\begin{tabular}{|c|c|c|c|c|c|c|c|}
\hline & \multicolumn{2}{|c|}{ Modelo 1} & \multicolumn{2}{|c|}{ Modelo 2} & \multicolumn{2}{|c|}{ Modelo 3} \\
\hline & & \multicolumn{6}{|c|}{ 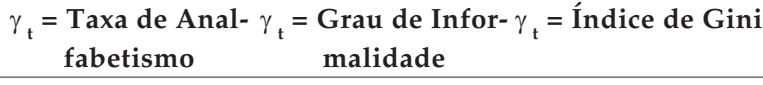 } \\
\hline & & $\beta$ & $\mathrm{t}$ & $\frac{\beta}{1329}$ & \multirow{2}{*}{8,64} & $\beta$ & $\mathrm{t}$ \\
\hline$\beta_{0}$ & (Constante) & $54,051^{* * *}$ & 6,00 & $132,92^{* * *}$ & & $0,430^{* * *}$ & 5,89 \\
\hline$\beta_{1}$ & $\begin{array}{l}\text { Grau de } \\
\text { informalidade }_{\text {it }}\end{array}$ & & & & & $0,002^{* * *}$ & 3,10 \\
\hline$\beta$ & $\begin{array}{l}\text { Taxa de } \\
\text { analfabetismo }_{\text {it }}\end{array}$ & & & 0,191 & 1,32 & & \\
\hline$\beta$ & Frequência escolar ${ }_{\text {it }}$ & $-0,334^{* * *}$ & $-7,59$ & $-0,157^{* *}$ & $-1,95$ & & \\
\hline$\beta_{2}$ & PMDB $_{i t}$ & $-0,345$ & $-0,80$ &,- 739 & $-1,07$ & $-0,009^{*}$ & $-1,70$ \\
\hline$\beta_{3}$ & PSDB $_{\text {it }}$ & $-0,160$ & $-0,35$ & $-2,126^{* * *}$ & $-2,78$ & $-0,009$ & $-1,60$ \\
\hline$\beta_{4}$ & $\mathrm{PFL}_{\text {it }}$ & $-0,275$ & $-0,62$ & $-1,613^{*}$ & $-1,86$ & $-0,011^{*}$ & $-1,74$ \\
\hline$\beta_{5}$ & $\mathrm{PDT}_{\text {it }}$ & $-0,261$ & $-0,57$ & $-0,161$ & $-0,20$ & $-0,013^{*}$ & $-1,76$ \\
\hline$\beta_{6}$ & $\mathrm{PSB}_{\text {it }}$ & 0,093 & 0,19 & $-0,733$ & $-0,86$ & $-0,017^{* *}$ & $-2,36$ \\
\hline$\beta_{7}$ & PPS $_{\text {it }}$ & $1,600^{* * *}$ & 2,94 & $-2,74^{* * *}$ & $-2,53$ & $-0,008$ & $-0,73$ \\
\hline$\beta_{8}$ & $\begin{array}{l}\text { Pequenos Partidos } \\
\text { de Direita }_{\text {it }}\end{array}$ & $-0,983^{* *}$ & $-1,97$ & $-0,632$ & $-0,75$ & $-0,007$ & $-0,91$ \\
\hline$\beta_{9}$ & $\begin{array}{l}\text { Votos no primeiro } \\
\text { turno }(\%)_{\text {it }}\end{array}$ & 0,009 & 1,26 & $-0,017$ & $-1,55$ & $0,0004^{* * *}$ & 2,71 \\
\hline$\beta_{10-21}$ & Efeito fixo temporal & \multicolumn{2}{|c|}{ Sim - Omitidas ${ }^{\mathrm{a}}$} & \multicolumn{2}{|c|}{ Sim - Omitidas } & \multicolumn{2}{|c|}{ Sim - Omitidas } \\
\hline$\beta_{22}$ & PIB per capita & $-0,135$ & $-0,75$ & $-0,617$ & $-1,49$ & 0,004 & 1,43 \\
\hline$\beta_{23}$ & Esgoto $_{\text {it }}$ & $-5,76^{* * *}$ & $-4,41$ & $-8,17^{* * *}$ & $-3,19$ & & \\
\hline$\eta_{i}$ & $\begin{array}{l}\text { Efeito Fixo de } \\
\text { Estados }\end{array}$ & \multicolumn{2}{|c|}{ Sim - Omitidas } & \multicolumn{2}{|c|}{ Sim - Omitidas } & \multicolumn{2}{|c|}{ Sim - Omitidas } \\
\hline & $\mathrm{R}^{2}$ & 0,98 & & 0,96 & & 0,81 & \\
\hline & Rho & 0,21 & & 0,42 & & 0,13 & \\
\hline & $\mathrm{N}$ de observações & 338 & & 338 & & 338 & \\
\hline
\end{tabular}

Fonte: Elaboração própria a partir dos dados do extinto Banco de Dados Eleitorais do Brasil (BDEB) e do Ipeadata.

***1\%; **5\%; ${ }^{* 10 \%}$.

a - A classificação "omitidas" indica que foram inseridas as dummies para efeito fixo (temporal e de estados), mas os resultados não estão aqui reportados por não serem substantivamente importantes para a análise.

Observa-se também que o grau de informalidade do mercado de trabalho apresentou significância estatística e sinal positivo como esperado. O resultado mostra que o grau de informalidade do mercado que indica a precariedade dos postos de trabalho produz impacto no nível de

DADOS - Revista de Ciências Sociais, Rio de Janeiro, vol. 56, nํ 3, 2013 
distribuição de renda. Para cada ponto percentual a mais no grau de informalidade em um determinado estado, haverá um aumento de 0,002 ponto percentual no Índice de Gini. Quanto mais informal estiver estruturado o mercado de trabalho, maior a desigualdade de renda daquele lugar, resultados estes que corroboram a visão clássica de que o setor informal do mercado de trabalho apresenta postos de trabalho de baixa qualidade, deixando os trabalhadores sem garantia de proteção social e com desigualdades nos níveis de renda. As evidências mostram que a informalidade do mercado de trabalho afeta a desigualdade nos estados, sendo interessante notar que as variáveis de educação e esgotamento sanitário perdem efeito no último modelo, mostrando a pertinência dos mecanismos causais indiretos aqui defendidos. Entretanto, nem todos os resultados são de fácil interpretação. Vejamos.

\section{Dos Partidos Políticos}

No que diz respeito aos partidos políticos, observou-se que eles produzem, sim, efeito significativo sobre a distribuição de renda nos estados. Como sugerido, afetam, primeiramente, as taxas de analfabetismo e o grau de informalidade. O primeiro modelo mostra que, entre $1992 \mathrm{e}$ 2006, o PPS, o PSB e o, então, PFL (atual Democratas - DEM) apresentaram, em seus governos estaduais, taxas de analfabetismo mais altas do que os governos petistas. Mais forte ainda são as diferenças apresentadas entre os partidos no que se refere ao grau de informalidade do mercado de trabalho: neste caso, o PSDB e o PPS apresentam níveis de informalidade significativamente mais baixos do que o PT - com coeficientes consideravelmente elevados. Em média, o PSDB e o PPS apresentam -1,50 e -2,90 pontos percentuais no grau de informalidade do que $o$ PT. Ao analisar o terceiro modelo, observamos evidências de que o PMDB, o PSDB, PFL e o PSB apresentam médias mais baixas em relação aos governos do PT, estatisticamente significativas, entre 1992 e 2006, o que significa que seus governos apresentaram patamares menores de desigualdade do que naqueles do PT.

Para se ter uma ideia da dimensão dos coeficientes apresentados cabe pensar que todo o legítimo movimento feito por acadêmicos, pesquisadores, políticos e demais interessados na recente queda de desigualdade de renda no Brasil dá-se no sentido da compreensão dos determinantes da queda de 0,0289 do Índice de Gini entre 2003 e 2007 (Hoffman, 2009:Tabela 6). Com base nessa referência, tem-se noção da magnitude das diferenças entre os partidos e o PT: destaca-se o PSB com 
$-0,017$ (a 5\%), em seguida o PDT com -0,013 (a 10\%) e, por fim, o PFL e o PMDB com -0,011 e -0,009 em um nível de confiança de 10\%, mantidos os demais fatores constantes. Dado que há o controle de efeito fixo dos estados governados é de se esperar que estejam controladas as características dos estados de cada partido. Isso permite inferir que a política estadual é substancialmente diferente da política no nível federal. Se estamos vendo que no nível nacional o PT foi o precursor de políticas redistributivas de renda baseadas na solidariedade nacional preconizada na Constituição de 1988, isso não aconteceu da mesma forma nos estados, o que nos sugere que há, sim, uma dinâmica política estadual dos partidos que os difere do nacional.

Evidências sugerem uma direção inversa da hipótese clássica: governos do PMDB, do PDT, do PFL e do PSB apresentam médias de Gini significativamente mais baixas do que as do PT, mantendo-se constante os demais fatores e controlando-se o efeito fixo de estados e de tempo. Todavia, como vimos, este resultado pode ser lido de mais de uma forma: a primeira, e mais importante para os fins desse trabalho, é confirmar que a Política no nível estadual importa, sim, para efeitos de redistribuição de renda, ou seja, é possível se inferir que as políticas educacionais e de qualificação para o mercado de trabalho realizadas no nível estadual potencializarão os efeitos das políticas redistributivas implementadas pelo governo federal e, além disso, podemos afirmar que os fatores políticos determinaram esses $\operatorname{processos}^{10}$.

Esse resultado se mostra especialmente interessante se se considera o período analisado. Em estudo anterior, Sátyro (2008) não encontra nenhum efeito significativo de partidos quando analisa provisão de políticas sociais nos estados entre 1986 e 2006, utilizando-se gastos sociais como proporção do total de despesas orçamentárias. Os resultados de Sátyro corroboram os achados internacionais que sugerem a perda da capacidade explicativa dos partidos diante do aumento de restrições institucionais e de pontos de veto a partir da segunda metade da década de 1990 (Kittel e Obinger, 2001; Armigeon et al., 2001; Castles, 2001). Para Sátyro, a política fiscal da era Fernando Henrique Cardoso constrangeu e homogeneizou os gastos governamentais no nível estadual, e assim os partidos perderam sua capacidade explicativa para a provisão de políticas sociais. Isto significa que os partidos têm esforços similares no que se refere à quantidade de gastos sociais. 
Ora, a presente análise tem um recorte temporal que foca exatamente o momento em que esses constrangimentos estão sendo impostos pelo governo central. Dessa forma, podemos afirmar que tanto a Política estadual importa para redistribuição de renda quanto as diferenças observadas em relação ao PT são bastante significativas, pois aparecem mesmo diante das restrições em relação aos gastos. Aparecem num momento em que todos estão sendo obrigados a gastar mais ou menos a mesma quantidade. Isso implica que podemos inferir que, independentemente da magnitude dos coeficientes apresentados pelos partidos, eles são muito significativos na medida em que apontam claramente para um esforço diferenciado no tipo de gasto entre os partidos no nível estadual, reforçando a ideia principal do argumento de que a política no nível estadual faz, sim, diferença na construção de uma sociedade menos desigual.

Uma segunda conclusão, que causa estranheza pela direção não esperada, é que esses partidos possuem políticas estaduais mais redistributivas do que os governos petistas. Entretanto, esse resultado nos remete à controvérsia citada anteriormente, levando-nos a um impasse em relação aos achados: o PT realmente apresenta níveis de desigualdade de renda incompatíveis com a teoria clássica? Ou há um problema de endogeneidade na hipótese aqui trabalhada e, na verdade, o que vemos é uma consequência e não uma causa? Dito de forma mais clara, os patamares mais altos de desigualdade encontrados nos governos petistas são função de um viés de atração e suporte a este partido em estados em que as condições iniciais eram piores? Resta pesquisar mais para responder adequadamente a este resultado.

\section{Da Competição Política}

Competição política também teve sua significância ressaltada nessa análise, com resultados que mostram que ela tem efeitos nas políticas redistributivas estaduais. Os resultados permitem afirmar que a concentração de votos em torno do candidato eleito no primeiro turno tem efeito direto na redistribuição de renda. Entretanto, a magnitude deste impacto na desigualdade de renda é baixa, tendo um coeficiente de 0,0004 em um nível de confiança de $1 \%$. O sinal positivo indica o movimento certo da direção causal, isto é, quanto mais concentrados os votos em um só candidato no primeiro turno dos governos estaduais, indicando menos competição política, mais desigualdade de renda. Por 
fim, observa-se que competição política não se apresentou significativa para o grau de informalidade, nem para a taxa de analfabetismo.

\section{CONCLUSÕES}

Um trabalho de pesquisa pode ter sua relevância a partir de dois critérios: o primeiro, teórico-acadêmico, entendido como uma contribuição para a explicação de aspectos dos sistemas social e político; o segundo, pela importância para a vida prática em função das consequências sociais, políticas e econômicas do objeto de pesquisa (King, Keohane e Verba, 1994). Este artigo pretende ajudar em pelo menos duas lacunas da Ciência Política brasileira: uma, que se refere ao aprofundamento das diferenças entre os estados no que tange à evolução da proteção social e suas consequências na conformação da desigualdade de renda; outra, que se refere à responsabilidade do arcabouço político-institucional nesse processo.

A maioria dos estudos recentes sobre desigualdade no Brasil foca no nível nacional e se restringe aos determinantes econômicos ou relativos ao mercado de trabalho sobre os processos de distribuição e redistribuição de renda, ou, ainda, aos programas de transferência de renda. Infelizmente, podemos afirmar sem receio que há muito pouca produção que se atém especificamente à correlação entre os indicadores políticos e a desigualdade de renda. Sabemos que, mesmo na Ciência Política internacional, há relativamente pouca produção com foco voltado para o nível estadual de governo. Os estudos existentes, em sua maioria, realizam análises comparativas entre países, ou realizam estudos de casos específicos, mas, raramente, privilegiam a comparação entre unidades subnacionais, o que leva a uma lacuna analítica sobre esse nível de análise. Por fim, as limitações teóricas e empíricas apresentadas pelos trabalhos que relacionam fatores políticos e desigualdade em geral justificam uma análise mais detalhada sobre o tema.

Os resultados nos permitem três conclusões em relação às hipóteses aqui trabalhadas: a primeira confirma nossa hipótese central de que a política no nível estadual importa para a redistribuição de renda, direta e indiretamente; a segunda, mostra que competição política afeta a desigualdade de renda, diretamente; e, a terceira, contraria as nossas expectativas ao mostrar evidências de que partidos de centro e de direita tiveram um efeito redistributivo maior do que os governos petistas no período analisado. Desse modo, apesar da inegável importância 
das políticas oriundas da arena de políticas redistributivas do governo federal, os partidos no nível estadual de governo produzem diferentes níveis de políticas redistributivas. Observamos que os partidos se diferenciam, sim, na implementação de políticas e que, não necessariamente, o PT possui uma tendência à implantação de políticas redistributivas nos estados, como esperado. O que vimos é que, mantendo-se os demais fatores constantes, no nível estadual, outros partidos promoveram mais igualdade do que os governos petistas. Mesmo que haja a necessidade de outros estudos para se confirmar esse resultado, ou mostrar o problema já apontado com a hipótese, ainda assim os resultados nos mostram que os partidos terão de escolher cada vez mais estratégias governativas que os diferenciem no nível estadual se quiserem construir um sistema partidário competitivo e programático.

Cabe enfatizar que o efeito dos partidos e da competição política nas políticas redistributivas nos estados aparecem (e se mostram robustos nos testes). Isso acontece mesmo diante das políticas fiscais restritivas impostas pelo governo federal durante o período aqui analisado onde podemos citar como exemplo a Lei de Responsabilidade Fiscal (LRF) e a Lei de Diretrizes Orçamentárias (LDO), que determinam as vinculações de verba e dão as competências de estados e municípios neste período. Mesmo quando os partidos nos estados não se diferem mais na quantidade de gastos sociais, como mostrado por Sátyro (2008), ainda há a opção de se diferenciarem pelo tipo de gasto feito.

As características políticas e do sistema partidário dos estados impactam na desigualdade de renda, sendo, assim, importantes para a construção de uma sociedade mais igualitária. Isso reforça a importância do estado como ente federativo de governo que pode fazer diferença na produção de bem-estar social e de proteção social da população brasileira. Os resultados encontrados por este estudo nos obrigam a aprofundar ainda mais nossas agendas de pesquisa nesta área. Traz-nos, em suma uma forte evidência de que o senso comum acadêmico está equivocado e que, apesar da indiscutível força do governo federal na elaboração de políticas públicas redistributivas e de seu papel neste sentido, é possível criá-las também no âmbito subnacional.

(Recebido para publicação em fevereiro de 2011)

(Reapresentado em maio de 2012)

(Aprovado para publicação em março de 2013) 


\section{NOTAS}

1. "Existem alguns limites à interpretação dos dados apresentados no gráfico 1. O primeiro é que a comparabilidade entre as PNADs da década de 1970 e as outras é baixa. O segundo é que parte da alta desigualdade observada no período hiperinflacionário é, em certo sentido, falsa. Isso ocorre porque a alta inflação, quando conjugada com a indexação imperfeita dos salários, gera aumentos na desigualdade medida por um corte transversal no tempo, tal como na PNAD, mas que desaparece quando se toma a média de rendimentos ao longo de um período maior, conforme demonstra Neri (1994). Finalmente, houve mudança de questionário entre 1990 e 1992, embora a percepção da renda não seja um dos itens mais afetados" (Soares, 2006:8).

2. Para se entender melhor o processo de descentralização no Brasil é importante consultar Arretche, que possui trabalhos mostrando a contradição do processo de descentralização das políticas sociais no Brasil que se restringe fortemente à execução das políticas, ficando com o governo federal as diretrizes e a coordenação. A autora discute também os condicionantes locais da descentralização (Arretche, 2000; 2006; 2007).

3. "As Secretarias Estaduais de Trabalho desempenhavam um papel estratégico na articulação e na implementação do PLANFOR nos estados, congregando os recursos provenientes do FAT com os das agências locais de educação profissional, especialmente, aquelas que eram financiadas com recursos públicos" (Peixoto, 2008:66).

4. "É importante recordar que a Resolução 126 do CODEFAT definiu as funções das Secretarias Estaduais de Trabalho e das Comissões Municipais de Emprego, em que as primeiras eram responsáveis pela elaboração e pela coordenação dos planos estaduais que deveriam ser submetidos às Comissões para homologá-los" (Peixoto, 2008:66).

5. “As Comissões Estaduais de Emprego - organismos tripartites e paritários, com representação do governo, empresariado e trabalhadores de cada Estado - eram responsáveis pelo levantamento das demandas locais de qualificação, assim como realizavam um trabalho de acompanhamento da execução dos cursos ofertados" (Peixoto, 2008:66).

6. O recorte temporal foi determinado pela disponibilidade de dados relativos ao mercado de trabalho - grau de informalidade e taxa de desemprego.

7. O PDS tornou-se PPR e o PPR tornou-se PPB.

8. Como já observado por Sátyro (2008:121): “A especificação AR1 pressupõe a existência de uma autocorrelação de ordem 1; sendo que autocorrelação é definida como sendo a correlação dos valores de uma variável no instante t com os valores, dessa mesma variável, defasados no tempo. Esse é um método específico para tratar erros autorregressivos, isto é, quando há dependência entre os grupos analisados. A aplicação desta técnica faz-se necessária quando, para analisar um determinado fenômeno no período " $\mathrm{t}$ ", pressupõe-se o conhecimento do nível do erro dessa ocorrência no período " $\mathrm{t}-1$ ", tanto quanto seu erro no período " $\mathrm{t}$ ". Há, deste modo, um processo autorregressivo que, resumidamente, assume a existência e corrige a autocorrelação dos painéis e das STCTs (Beck e Katz, 1995)".

9. Apesar de o período analisado ter 15 anos, os dados são relativos a 13 anos, uma vez que para os anos de 1994 e 2000 não há dados disponíveis; dessa forma chegaríamos a

DADOS - Revista de Ciências Sociais, Rio de Janeiro, vol. 56, nํ3, 2013 


\section{Natália Guimarães Duarte Sátyro}

351 casos (27x13=351). Com a exclusão do DF reduzimos para 338 casos (26x13), ainda muito acima da faixa dos 200 casos utilizados em trabalhos aqui citados.

10. Importante ressaltar que resultados muito semelhantes são encontrados mesmo sem a introdução dos controles temporais e dos efeitos fixos dos estados, o que dá a noção da robustez e da estabilidade do modelo aqui apresentado e, portanto, das relações aqui demonstradas. 


\section{REFERÊNCIAS BIBLIOGRÁFICAS}

ARMINGEON, Klaus; BEYELER, Michelle e BINNEMA, Harmen. (2001), The Changing Politics of the Welfare State. A Comparative Analysis of Social Security Expenditures in 22 OECD Countries, 1960-1998. Berna, University of Berne, Institute of Political Science, inédito.

ARRETCHE, Marta. (2006), “Federalismo e Políticas Sociais no Brasil: Problemas de Coordenação e Autonomia", in E. Saravia e E. Ferrarezi (orgs.), Políticas Públicas. Brasília, ENAP, vol. 2, pp. 91-110.

(2000), Estado Federativo e Políticas Sociais: Determinantes da Descentralização. Rio de Janeiro, Revan.

e MARQUES, Eduardo. (2007), “Condicionantes Locais da Descentralização das Politicas de Saúde", in G. Hochman; M. Arretche e E. Marques (orgs.), Políticas Públicas no Brasil. Rio de Janeiro, Fiocruz, pp. 173-204.

BARRET, Patrick; CHAVEZ, Daniel e RODRIGUEZ-GARAVITO, César (orgs.). (2008), The New Latin America Left: Utopia Reborn. London, Pluto Press.

BARROS, Ricardo et al. (2007), "A Queda Recente da Desigualdade de Renda no Brasil”. Texto para Discussão 1258, Rio de Janeiro, IPEA.

BARROS, Ricardo Paes de; FOGUEL, Miguel N. e ULYSSEA, Gabriel. (2007), Desigualdade de Renda no Brasil: Uma Análise da Queda Recente. Brasília, IPEA, vol. 1.

. (2008), Desigualdade de Renda no Brasil: Uma Análise da Queda Recente. Brasília, IPEA, vol. 2.

BECK, Nathaniel e KATZ, Jonathan. (1995), “What to Do (and Not to Do) with Time-Series Cross-Section Data". American Political Science Review, no 89, pp. 634-647.

BLANCO, Luisa e GRIER, Robin. (2011), “Explaing the Rise of the Left in Latin America”. Working Papers, Paper 24, Pepperdine University, School of Public Policy.

BOSCHETTI, Ivanete. (2006), Seguridade Social e Trabalho. Paradoxos na Construção das Políticas de Previdência e Assistência Social no Brasil. Brasília, Letra Livres/Editora da UnB.

BRADLEY, David et al. (2003), "Distribution and Redistribution in Postindustrial Democracies". World Politics, vol. 55, no 2, pp. 193-228.

CASTLES, Frances. (1982), The Impact of Parties: Politics and Policies in Democratic Capitalist States. London, Sage.

. (2001), "On the Political Economy of Recent Public Sector Development". Journal of European Social Policy, vol. 11, no 3, pp. 195-211.

CÊA, Georgia Sobreira dos Santos. (2007), “A Qualificação Profissional como Instrumento de Regulação Social: Do PLANFOR ao PNQ", in G. S. S. Cêa (org.), O Estado da Arte da Formação do Trabalhador no Brasil: Pressupostos e Ações Governamentais. Cascavel, EdUnioeste, pp.187- 226.

CHHIBBER, Pradeep e NOORUDDIN, Irfan. (2004), “Do Party Systems Count? The Number of Parties and Government Performance in the Indian States". Comparative Political Studies, vol. 37, no 2, pp. 152-187.

DADOS - Revista de Ciências Sociais, Rio de Janeiro, vol. 56, nº 3, 2013 


\section{Natália Guimarães Duarte Sátyro}

DEDECCA, Claudio S. (2007), “A Redução da Desigualdade no Brasil, uma Estratégia Complexa”, in R. P. de Barros; M. Foguel e G. Ulyssea (orgs.), Desigualdade de Renda no Brasil: Uma Análise da Queda Recente. Brasília, IPEA, vol. 1.

FERREIRA, Francisco H. G. et al. (2007), “Ascensão e Queda da Desigualdade de Renda no Brasil: uma Atualização para 2005", in R. P. de Barros; M. N. Foguel e G. Ulyssea (orgs.), Desigualdade de Renda no Brasil: Uma Análise da Queda Recente. Brasília, IPEA, vol. 1 .

GIAMBIAGI, Fábio e FRANCO, Samuel. (2007), “Esgotamento do Papel do Salário Mínimo como Mecanismo de Combate à Pobreza Extrema". Texto para Discussão 1290. Rio de Janeiro, IPEA.

GUPTA, Arnab e DAMANIA, Richard. (2004), "Political Competition, Welfare Outcomes and Expenditures on Human Development: the Experience of a Democracy". Econometric Society, no 147, pp. 1-27.

HICKS, Alexander M. e SWANK, Duane H. (1992), "Politics, Institutions, and Welfare Spending in Industrialized Democracies, 1960-82". American Political Science Review, vol. 86, no 3, pp. 658-674.

HOFFMANN, Rodolfo. (2007), “Transferências de Renda e Redução da Desigualdade no Brasil e em Cinco Regiões, entre 1997 e 2005", in R. P. de Barros; M. N. Foguel e G. Ulyssea (orgs.), Desigualdade de Renda no Brasil: uma Análise da Queda Recente. Brasília: IPEA, vol. 1, pp. 17-40.

IVERSEN, Torben e SOSKICE, David. (2006), "Electoral Institutions and the Politics of Coalitions: Why Some Democracies Redistribute More than Others". American Political Science Review, vol. 100, no 2, pp.165-181.

KENWORTHY, Lane e PONTUSSON, Jonas. (2005), “Rising Inequality and the Politics of Redistribution in Affluent Countries". Perspectives on Politics, vol. 3, no 3, pp. 449-471.

KING, Gary; KEOHANE, Robert e VERBA, Sidney. (1994), Designing Social Inquiry. Scientific Inference in Qualitative Research. Princeton, Princeton University Press.

KITTEL, Bernhard e OBINGER, Herbert. (2002). "Political Parties, Institutions, and the Dynamics of Social Expenditure in Times of Austerity". MPIfG Discussion Paper 02/1, February.

KLINK, Jeroen e LÉPORE, Wendell C. (2002), “Regionalismo e Reestruturação no Grande ABC Paulista - São Paulo: Uma Perspectiva Brasileira de Governança Metropolitana". Disponível em http://www.metodista.br/ppc/revista-ecco/revista-ecco-01/regionalismo-e-reestruturacao-no-grande-abc-paulista-2013-sao-paulo-uma-perspectiva-brasileira-de-governanca-metropolitana / acesso em 5/8/2013.

LANGONI, Carlos Geraldo. (1973), Distribuição da Renda e Desenvolvimento Econômico do Brasil. Rio de Janeiro, Editora Expressão e Cultura.

LEVITSKY, Steven e ROBERTS, Kenneth M. (orgs.). (2011), The Resurgence of the Latin American Left. Baltimore, Johns Hopkins University Press.

LOWI, Theodor. (1964), “American Business, Public Policy, Case Studies and Political Theory". World Politics, no 16, pp. 677-715. 
. (1972). "Four Systems of Policy, Politics, and Choice". Public Administration Review, vol. 32, no 4, pp. 298-310.

PEIXOTO, Patrícia E. (2008), Do PLANFOR ao PNQ: Uma Análise Comparativa sobre os Planos de Qualificação no Brasil. Dissertação de Mestrado. Vitória, Universidade Federal do Espírito Santo.

PONTUSSON, Jonas; RUEDA, David e WAY, Christopher. (2002), “Comparative Political Economy of Wage Distribution: The Role of Partisanship and Labour Market Institutions". British Journal of Political Science, vol. 32, pp. 281-308.

RAMOS, Lauro e VIEIRA, Maria Lúcia. (2001), Desigualdade de Rendimentos no Brasil nas Décadas de 80 e 90: Evolução e Principais Determinantes. Texto para Discussão, no 803. Rio de Janeiro, IPEA.

RIBEIRO, Leandro M. (2005), Partidos e Políticas Sociais nos Municípios Brasileiros (1996-2003). Tese de Doutorado em Ciência Política. Rio de Janeiro, Instituto Universitário de Pesquisas do Rio de Janeiro/Universidade Candido Mendes.

SALM, Cláudio. (2007), “Sobre a Recente Queda da Desigualdade de Renda no Brasil: uma Leitura Crítica”, in R. P. de Barros, M. N. Foguel e G. Ulyssea (orgs.), Desigualdade de Renda no Brasil: uma Análise da Queda Recente. Brasília, IPEA, vol. 1, pp. 279-298.

SÁTYRO, Natalia G. D. (2008), Política e Instituições e a Dinâmica das Políticas Sociais nos Estados Brasileiros: Uma Análise após a Redemocratização. Tese de Doutorado em Ciência Política. Rio de Janeiro, Instituto Universitário de Pesquisas do Rio de Janeiro/Universidade Candido Mendes.

e SOARES, Sergei. (2009), Transferência de Renda no Brasil: Uma Análise do Impacto do Bolsa Família e do BPC na Redução das Desigualdades nos Estados Brasileiros entre 2004 e 2006. Texto para Discussão 1435. Rio de Janeiro, IPEA.

SCHEVE, Kenneth e STASAVAGE, David. (2009), "Political Institutions, Partisanship, and Inequality in the Long Run". World Politics, vol. 61, no 2, pp. 215-253.

SOARES, Fábio Veras et al. (2006), "Programas de Transferência de Renda no Brasil: Impactos sobre a Desigualdade". Texto para Discussão 1228. Brasília, IPEA.

SOARES, Sergei (2006), “Distribuição de Renda no Brasil de 1976 a 2004 com Ênfase no Período 2001 e 2004". Texto para Discussão 1166. Brasília, IPEA.

et al. (2007), Programas de Transferência Condicionada de Renda no Brasil, Chile e México: Impactos sobre a Desigualdade. Texto para Discussão 1293. Brasília, IPEA.

DADOS - Revista de Ciências Sociais, Rio de Janeiro, vol. 56, n 3, 2013 


\author{
ABSTRACT \\ State Policy and Inequality: Why Do Some States Redistribute More Than \\ Others?
}

The aim of this study was to analyze variation in income inequality patterns between Brazilian states as a consequence of the political and institutional framework. The article contends that state-level political factors affect income redistribution through the promotion of human capital, i.e., investment in education, and investment in professional training policies or even policies to make regional areas more attractive to private investment. The study covers all states of Brazil and the Federal District from 1992 to 2006 and uses Prais-Winsten regression model estimations with panel corrected standard error (PCSE-AR1). The results show that despite the restrictions imposed on the states in this period, political competition and political parties at the state level of government produced different redistribution patterns. However, the article shows controversial results as to the role of the left and suggests the need for further research.

Key words: political party; state policy; income inequality

\title{
RÉSUMÉ \\ Politique des États de l'Union et Inégalités: Pourquoi certains États Redistribuent-ils Mieux le Revenu?
}

Dans cet article, on examine la variation des types d'inégalité du revenu dans les États du Brésil, issue de la charpente politico-institutionnelle du pays. On avance que les facteurs politiques à l'échelon de chaque État agissent sur la distribution des revenus, aussi bien par l'amélioration du capital humain, c'est-à-dire en investissant dans l'éducation, qu'en le faisant dans des politiques de formation professionnelle ou encore dans des politiques qui rendent les espaces régionaux plus attirants pour les investissements privés. Cette étude couvre tous les États du Brésil ainsi que le Distrito Federal pendant la période 1992-2006. L'analyse empirique s'est servie d'estimations de modèles de régression Prais-Winsten avec panel corrected standard error model (PCSE-AR1). Selon les résultats, malgré les restrictions financières imposées aux États pendant cette période, la compétition politique et les partis des États à leur niveau gouvernemental n'ont pas produit les mêmes modèles de redistribution. On trouve pourtant des résultats controversés en ce qui concerne le rôle de la gauche, ce qui suggère la poursuite de cette étude.

Mots-clés: parti politique; politique des États de la Fédération; inégalité des revenus 